Conclusions Mediastinitis should also be considered in patients with sternal wound infections after heart surgery. Aggresive surgical and medical treatment is essential.

\section{PO-0021 WITHDRAWN}

\section{PO-0022 ASSESSMENT OF CORONARY ARTERY IN A MURINE MODEL OF KAWASAKI DISEASE BY ECHOCARDIOGRAPHY}

ZD Du, H Yang, W Shangguan, Y Zhang. Cardiology, Beijing Children's Hospital Capital Medical University, Beijing, China

\subsection{6/archdischild-2014-307384.701}

Introduction This study sought to assess the changes of coronary artery complications and cardiac function in the murine model of Kawasaki disease (KD) with a high frequency ultrasound system.

Methods Lactobacillus casei cell wall extract (LCWE) was prepared, and injected to $\mathrm{C} 57 \mathrm{BL} / 6$ mice intraperitoneally to induce $\mathrm{KD}$. Totally 40 mice were categorised into KD model group and the control group randomly. On days 10, 21 and 60, coronary artery were measured by echocardiography. Left ventricular enddiastolic diameter (LVIDd), end-systolic diameter (LVIDs), ejection fraction (EF), fractional shortening (FS) and blood flow velocity of atrio-ventricular valve during early diastole (E)/atrial contraction (A) were also assessed.

Results Echocardiography detected coronary artery and measured cardiac function in all mice. There was a high density echo images around the coronary artery wall at 10 days and 21 days in the KD group, $4(20 \%)$ presented local coronary artery aneurysm at 14 days and 21 days. The diameter of left coronary artery in KD group $(0.46 \pm 0.11 \mathrm{~mm}$ on D10, $0.47 \pm 0.09 \mathrm{~mm}$ on D21) was larger than controls $(0.32 \pm 0.14 \mathrm{~mm}$ on $\mathrm{D} 10$, $0.36 \pm 0.06 \mathrm{~mm}$ on $\mathrm{D} 21$, all $\mathrm{p}<0.01)$. There were no significantly differences in measurement of cardiac function.

Conclusions Coronary artery and cardiac function could be assessed easily by echocardiography in murine model of $\mathrm{KD}$. Murine model of KD established by LCWE was shown similar natural progression on coronary artery abnormalities with $\mathrm{KD}$ patient.

\section{PO-0023 WARFARIN AND ASPIRIN COMBINATION THERAPY FOR GIANT CORONARY ARTERIAL ANEURYSM IN KAWASAKI DISEASE}

ZD Du, Y Zheng. Cardiology, Beijing Children's Hospital Capital Medical University, Beijing, China

\subsection{6/archdischild-2014-307384.702}

Introduction This study sought to assess whether warfarin and aspirin combination therapy can prevent cardiovascular events in children with giant coronary artery aneurysm (CAA) caused by Kawasaki disease.

Method Children with giant CAA secondary to Kawasaki disease in our hospital were included. They were randomly divided into warfarin group (warfarin + aspirin) and control group (aspirin only). The dose of warfarin was adjusted by INR (1.5-2.0). Follow-up time included 2nd week, 1st month, 3rd month, 6th month and every 6 months afterward. Clinical data and complications were recorded.

Result Sixty-five children were included with age of 3 months to 13 years. CAA most commonly occurs in right coronary artery, then left anterior descending, and main trunk. Left circumflex artery is rarely affected. CAA in 17 cases $(53.1 \%)$ retracted in warfarin group, 5(41.7\%)in controls. During followup, 2 children $(6.3 \%)$ presented with intracoronary thromboses in warfarin group, $3(25 \%)$ in controls. One case in warfarin group suffered myocardial infarction, $3(25 \%)$ in control. Two children in control group died, while none in warfarin group. Coronary artery stenosis occurred in 2 children (16.7\%) in controls, while one in warfarin group. Bleeding event occurred in 9 children including 1 with subarachnoid haemorrhage in warfarin group while only in 3 in the controls.

Conclusion Warfarin therapy could decrease the risk of thrombosis, myocardial infarction and mortality. Minor bleeding event is common and need to be monitored.

\section{PO-0024 CLINICAL COURSE FEATURES OF NEWBORNS WITH CONGENITAL HEART DEFECTS: 15 YEARS' EXPERIENCE OF OUR CENTRE}

${ }^{1} \mathrm{O}$ Filaretova, ${ }^{2} \mathrm{M}$ Tumanyan, ${ }^{2} \mathrm{~V}$ Chechneva, ${ }^{2} \mathrm{~A}$ Anderson, ${ }^{2} \mathrm{E}$ Levchenko, ${ }^{2} \mathrm{~A}$ Kotova, ${ }^{2} \mathrm{JU}$ Butrim, ${ }^{3} \mathrm{~A}$ Kim, ${ }^{4} \mathrm{~L}$ Bokeria. ${ }^{1}$ Pediatric Cardiology Course at the Chair of Cardiovascular Surgery and Interventional Cardiology, Bakoulev Scientific Center for Cardiovascular Surgery, Moscow, Russia; ${ }^{2}$ Department of Intensive Cardiology for Newborns and Infants with Congenital Heart Disease, Bakoulev Scientific Center for Cardiovascular Surgery, Moscow, Russia; ${ }^{3}$ Department of Reconstructive Surgery of Newborns and Infants, Bakoulev Scientific Center for Cardiovascular Surgery, Moscow, Russia; ${ }^{4}$ The Head and Chairman, Bakoulev Scientific Center for Cardiovascular Surgery, Moscow, Russia

\subsection{6/archdischild-2014-307384.703}

Aim A retrospective cohort study was made as well as a comparative analysis of the medical and surgery results of newborns with congenital heart defects (CHD).

Materials 2440 newborns (median: 8 days [IQR:2-18 days], $3.25 \mathrm{~kg}$ [IQR:0,85-6,5 kg]) underwent surgical repair in the Bakoulev SCCVS between 1999 and 2013. At the time of corrective surgery 1104 (51\%) patients were up to 7 days old with critical CHD (median:2,9 kg [IQR:0,85-5,1 kg]). Among them $526(48 \%)$ were 1 day old. All newborns were divided into two groups by the number of surgical repairs performed per year: group 1-up to 100 patients $(1999-2004, \mathrm{n}=305)$, and group 2 more than 100 patients $(2005-2013, \mathrm{n}=2135)$. The survival analysis was made according to Kaplan and Meier method (K-M).

Results The CHD range was primarily represented by aortic obstructive lesions (622-25,5\%), transposition complexes (488$20 \%)$, tetralogy of Fallot complexes (193-7,9\%), critical pulmonary stenosis/atresia with intact septum (183-7,5\%) and others. $47 \%$ undergone complete repair of CHD. The following risk factors $(n=6)$ for increased post-operative mortality by multivariate analysis $(\mathrm{p}=0.0001)$ were identified. Progressive deteriorate on of the surgical results survival increased with number of risk factors, regardless of their combination (ROC-curve: AUS $=0.8073, \mathrm{~K}-\mathrm{M} \mathrm{p}=0.00001) .22$ diagnostic/treatment strategies of critical neonates with CHD were developed. Over a period of study the capacity of surgery care was expanded (p.001), including complete repair CHD (42\% vs 49\%,p = $0.01)$. Morbidity of critical neonates decreased in both preoperative $(21 \%$ vs $0,01 \% \mathrm{p}=0.0002)$ and postoperative period (K-M $\mathrm{p}=0.000001)$. Actuarial survival rate was improved both for 